\title{
Form Completed by (Signature)
}

National Cancer Institute

\section{Source}

National Cancer Institute. Form Completed by (Signature). NCI Thesaurus. Code C157097.

A directive to provide the signature of the individual completing the form. 